\title{
Evaluation of stress distribution in nickel- titanium rotary instruments with different geometrical designs subjected to bending and torsional load: a finite element study
}

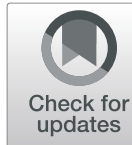

Manar Galal and Tamer M. Hamdy ${ }^{*}$ (D)

\begin{abstract}
Introduction: Geometrical designs of nickel-titanium (NiTi) rotary instruments have a considerable influence on their mechanical performance, and thereby have the tendency to fracture.

Aim: To evaluate the effect of cross-sectional geometry, pitch, taper, and off-center cross-section on the stress distribution in NiTi instruments under bending and torsion conditions using finite element analysis (FEA).

Materials and methods: Eleven theoretical three-dimensional finite element (FE) models of rotary instruments were constructed and divided according to the geometric design tested into; group 1 (cross-section geometry): four FE models with four different cross-section designs (triangle, convex triangular, parallelogram, and rectangle). Group 2 (pitch): three FE models with different pitches (5, 10, and 15 threads). Group 3 (taper): two FEA models with two different tapers (0.04 and 0.06). Group 4 (centering): two FEA models (off-centered and centered cross section). The behavior of the instrument under bending and torsional conditions was analyzed mathematically in SolidWorks software package.

Results: The pattern of stress distribution was varied by altering cross-sectional geometry, pitch, taper, and offcenter cross section.

Conclusion: No single geometrical design could be beneficial for all stress conditions. To decrease the stress accumulation during bending of rotary files in curved root canals, the rotary NiTi instruments should be designed with rectangle cross-section configuration, low pitch, reduced taper, and with centered cross section. This design improved the flexibility of rotary NiTi instruments. However, to improve the torsional resistance during root canal preparation of narrow canals, the file should be designed with parallelogram cross-sectional configuration, low pitch, increased taper, and eccentric cross-section design.
\end{abstract}

Keywords: Rotary files, NiTi, Design, Torsion, Bending, Stress distribution, Cross section, Pitch, Taper, Off-center

\section{Background}

One of the major problems during root canal preparation is instrument fracture. Instruments may fracture at different levels of stress, so various types of NiTi rotary endodontic instruments systems have been developed to

\footnotetext{
*Correspondence: dr_tamer_hamdy@yahoo.com

Researcher, Restorative and Dental Materials Department, National Research Centre (NRC), El Bohouth St., 12622 Dokki, Giza, Egypt
}

overcome this problem. The geometrical design of the NiTi rotary instruments dictates their mechanical behavior and fracture tendency (Ha et al. 2016, 2017; Hamdy et al. 2019).

The fracture of rotary endodontic instruments during endodontic treatment of curved root canals is often considered an enigma for endodontic practitioner. Mainly, they arise on exceeding torsional or bending stresses

\section{Springer Open}

() The Author(s). 2020 Open Access This article is licensed under a Creative Commons Attribution 4.0 International License, which permits use, sharing, adaptation, distribution and reproduction in any medium or format, as long as you give appropriate credit to the original author(s) and the source, provide a link to the Creative Commons licence, and indicate if changes were made. The images or other third party material in this article are included in the article's Creative Commons licence, unless indicated otherwise in a credit line to the material. If material is not included in the article's Creative Commons licence and your intended use is not permitted by statutory regulation or exceeds the permitted use, you will need to obtain permission directly from the copyright holder. To view a copy of this licence, visit http://creativecommons.org/licenses/by/4.0/. 
during function (Rzhanov and Belyaeva 2012). Therefore, torsion and bending are considered as two essential parameters of the endodontic files to ensure good performance and safety (McGuigan et al. 2013).

Raw materials, design, and manufacturing process can have a significant impact on instrument fracture (Shen et al. 2016; Gavini et al. 2018). Fracture of the NiTi rotary endodontic instrument may occur due to repeated bending stresses (compressive and tensile) accumulated at the point of maximum stress of the file in a curved root canal. Torsional fracture arises when the tip of the file becomes locked in the root canal, while the shank of the rotary instrument continues to rotate (Kim et al. 2012).

The procedure of NiTi rotary instruments manufacture influences their functional quality. The geometrical design of NiTi rotary instruments affects the clinical performance and durability. Consequently, geometric optimization is a platform to improving the fracture resistance of NiTi rotary instruments. The geometrical optimization needs to study each variation in design separately to achieve the most promising design (Ruddle et al. 2013).

Although there have been considerable developments in the design and manufacturing techniques of NiTi rotary instruments, instrumental fracture and separation remains a concern, particularly in severely curved root canals. Several investigations have exposed that both torsional stiffness and bending flexibility of a rotary endodontic file depend on the geometrical design such as cross-sectional design, pitch, taper of radial lands rake angles tip and off-center cross section (Basheer Ahamed et al. 2018).

Finite element analysis study is a beneficial approach to evaluate the mechanical performance of endodontic files and stress distribution. Moreover, it creates a more controlled condition, allowing evaluation of each geometrical design parameter separately (Tsao et al. 2013; Jiang et al. 2018).

In terms of cross-sectional shape, various kinds of NiTi rotary system have been hosted in the market, each having a unique cross-sectional shape that has a different behavior on stress distribution and, hence fracture tendency. Four cross-sectional shapes may be achieved such as convex triangle, triangle, rectangular, and parallelogram (Medha et al. 2014). A cross-section shape of NiTi rotary instruments is the most critical parameter affecting the instrument fracture, hence lifespan (Cheung et al. 2011).

During rotary movement of endodontic instruments, contact between the instrument and root canal walls generates internal stresses in the instrument and on the

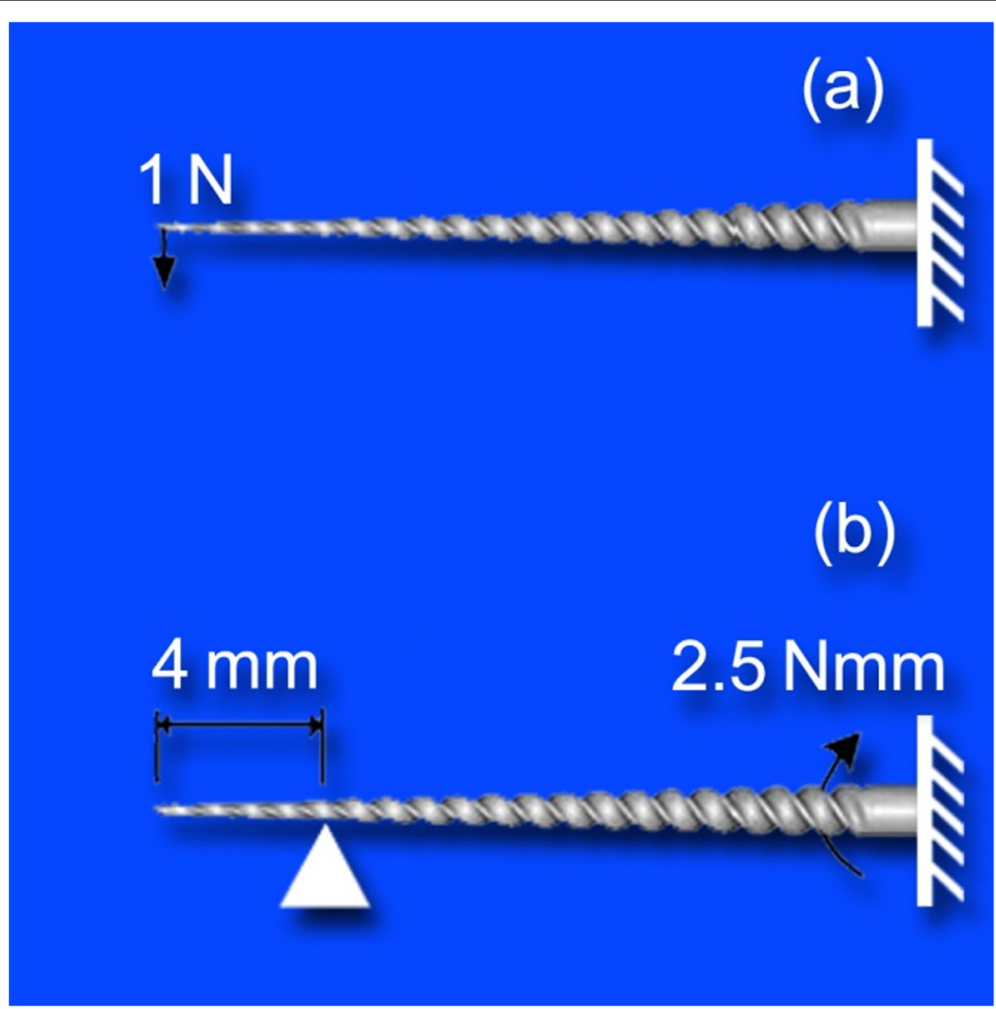

Fig. 1 Experimental simulated conditions diagram. a Cantilever bending with a concentrated load of $1 \mathrm{~N}$ applied to the instrument tip. b Shear moment of $2.5 \mathrm{~N} \mathrm{~mm}$ applied to the shaft with the instrument fixed rigidly at $4 \mathrm{~mm}$ from the tip 
root canal wall. While this force is essential for tooth cutting, it can cause a screw-in effect (an apical driving force) that may cause over extension of the instrument beyond the tooth apex (Ha et al. 2016). Geometrically, parallelogram (slender rectangular) and rectangular cross-sectional instruments (i.e., one- or two-point contacts) showed lower screw-in forces than triangular and convex triangular cross-sectional instruments (threepoint symmetrical contacts) (Kwak et al. 2019). A previous study showed that triangular cross sections result in more flexibility than square designs for the same file taper and diameter (Versluis et al. 2012).

Pitch of the file refers to the number of flutes per unit length. It was revealed that reducing pitch (increasing threads) constantly reduced the rigidity (stiffness) of the files. Thus, increasing their flexibility with marked decrease in the internal stress of the file (Baek et al. 2011; Versluis et al. 2012). Taper is the increase in the diameter of file per millimeter increase in length. Taper is one more feature of file design. It has been shown that increased taper will increase file rigidity and may produce a higher screw-in effect (Kwak et al. 2019).

Recently, an off-centered cross-sectional design was introduced to some endodontic files such as Revo-S system and ProTaper Next. The new design depends on deviation of the rotational center from being in the center of the cross section when compared with conventional concentric rotary conventional $\mathrm{Ni}-\mathrm{Ti}$ file. The modified off-centered rotational architecture features produces a bombastic motion of the instrument inside root canal (snake-like) that decreases the creation of the stress upon the rotational movement. Thus, reducing contact of the instrument with wall of canal. Moreover, it creates more room for easier debris removal (Pasqualini et al. 2015). There are no currently available clinical studies, until now, regarding the stress patterns of the off-centered design of the endodontic instruments.

There are demands to revolutionize the designs and metallurgy of the NiTi rotary instruments to overcome the problem of fracture of the instruments on use. Therefore, the aim of the current study was to evaluate imaginary innovative geometrical design modalities (cross-sectional geometry, pitch, taper, and off-center cross section) on the stress distribution in NiTi instruments under bending and torsion conditions using finite element analysis (FEA).

\section{Materials and methods}

Eleven theoretical three-dimensional FE models of rotary instruments were constructed and divided according to

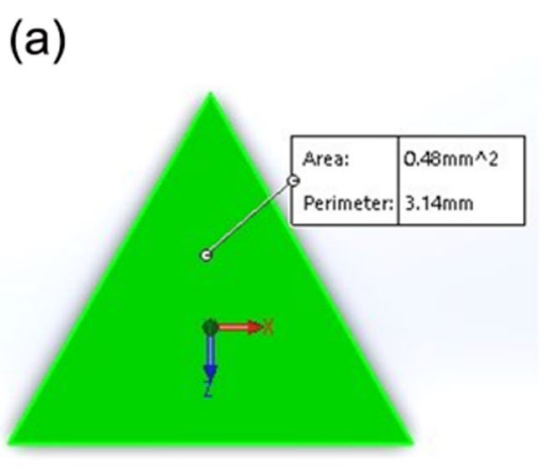

(c)

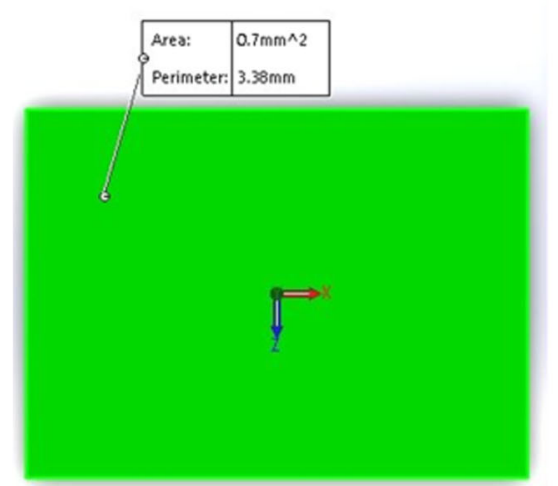

(b)

(d)

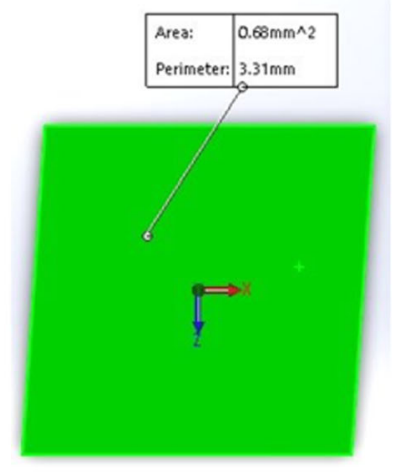

Fig. 2 A 2D drawing of different designed file cross section. a Triangle cs. b Convex triangular cs. c Rectangle cs. d Parallelogram cs 


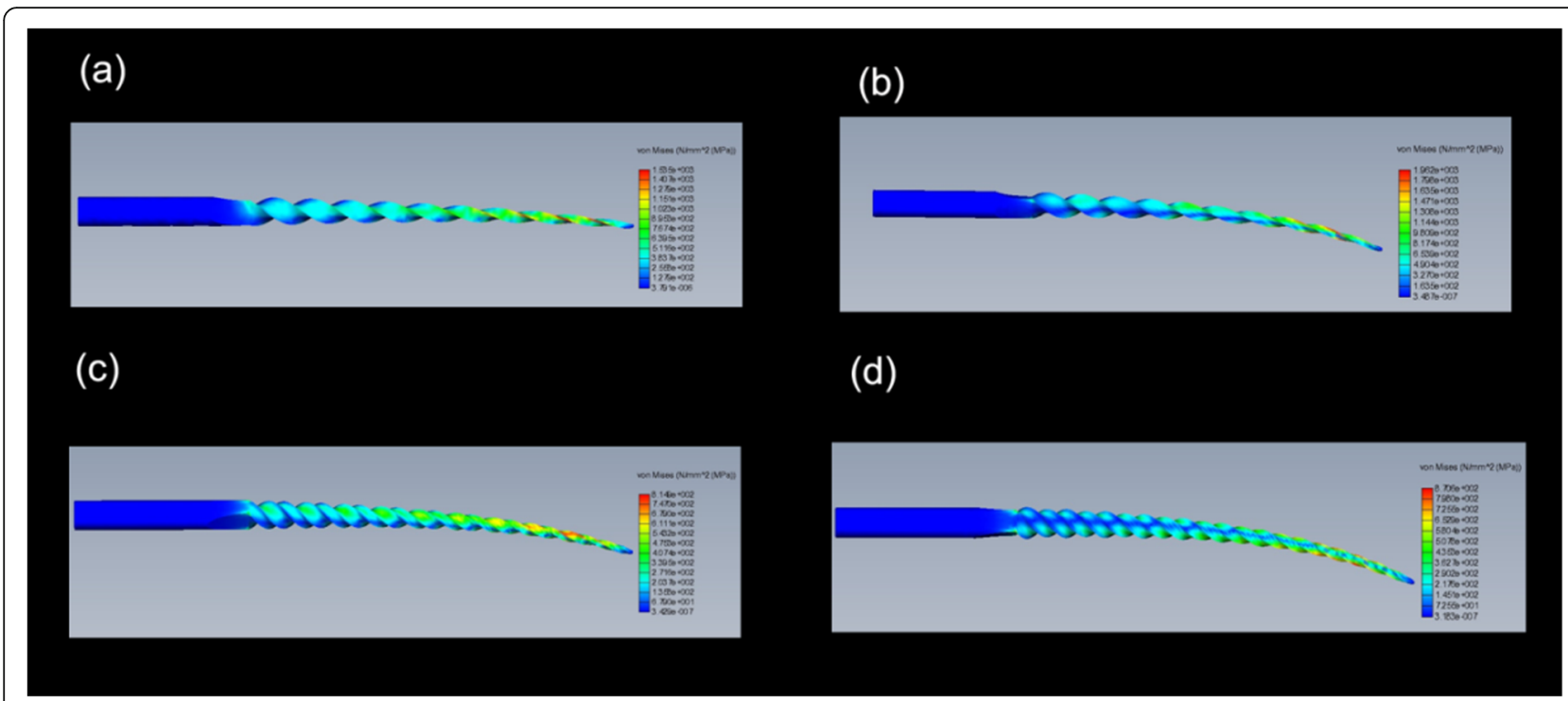

Fig. 3 Stress distribution during bending of different tested file cross sections. a Triangular cs. b Convex triangle cs. c Rectangular cs. d Parallelogram cs

tested geometrical design into four groups. Group 1 (cross-section geometry): four FE models with four different cross-section designs (triangle, convex triangular, rectangle, and parallelogram) but with same taper and pitch. Group 2 (pitch): three FE models with triangular cross section and $4 \%$ taper were created each one with different pitch $(5,10$, and 15 threads). Group 3 (taper): two FEA models with same geometrical cross-section design (triangular) and same pitch, both models differed only in the tapers (0.04 and 0.06). Group 4 (centricity): two FEA models with similar rectangular cross section and similar pitch and taper, they differ only in the centricity of the cross section (off-centered and centered cross section). Therefore, finite element analysis offered the advantage of changing each time only one parameter while fixing the other features.

\section{FE modeling of NiTi rotary files}

The digitalized 3D geometric models were created using the following steps: the file cross section was drawn in 2D using CAD, SolidWorks software package (SolidWorks Premium 2018 x64 Edition, USA). The 2D file with (.prt) extension was converted into Stereolithographic (.stl)

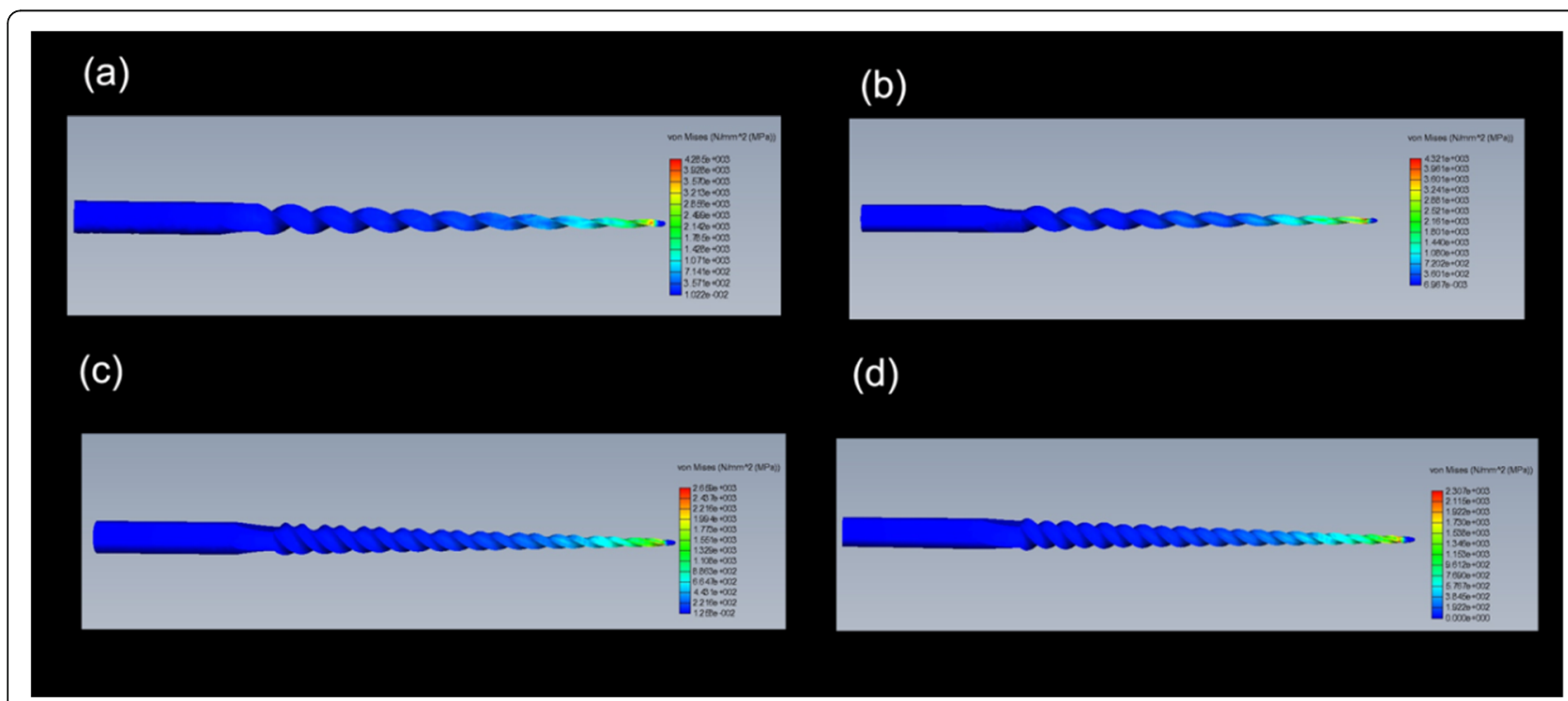

Fig. 4 Stress distribution during torsion of different tested file cross sections. a Triangular cs. b Convex triangle cs. c Rectangular cs. d Parallelogram cs 
extension to be readable by programming software (MATLAB, R2014b software) (Galal et al. 2015).

The STL file was imported to MATLAB software to be converted into Matrix form that reflects the 2D geometry. Building of 3D model in form of sections was performed by MATLAB software using the following unique imaginary different design data: cross section (cs), pitch, taper, and off-center cross section. The 3D file models were finalized by building both tip and shaft of the file using solid works software package. Meshing of the 3D models was done by (Cosmos, SolidWorks software package) using curvature-based mesh

\section{Experimental conditions of simulation}

The mechanical behaviors of the different models were analyzed mathematically using SolidWorks software package under the following under bending and torsional simulated conditions (Fig. 1):
(A). Cantilever bending with a constant loaddeformation was simulated in the form of cantilever bending by applying a concentrated load of $1 \mathrm{~N}$ at the tip of the file with its shaft held rigidly in place. The von Mises stress distribution was evaluated (Kim et al. 2009b; Necchi et al. 2010) (Fig. 1a).

(B). Application of a shear moment was simulated in the form of torsion by applying a load of $2.5 \mathrm{~N} \mathrm{~mm}$ at the shaft in a clockwise direction normal to the long axis of the file, though the last $4 \mathrm{~mm}$ of the tip was constrained rigidly. The stress distribution was evaluated (Kim et al. 2009b; Necchi et al. 2010) (Fig. 1b).

\section{Testing of different design features Cross-section configuration}

Four different models were created with the same taper (0.06) and the same pitch (10 threads), but with different four cross-sectional configurations and

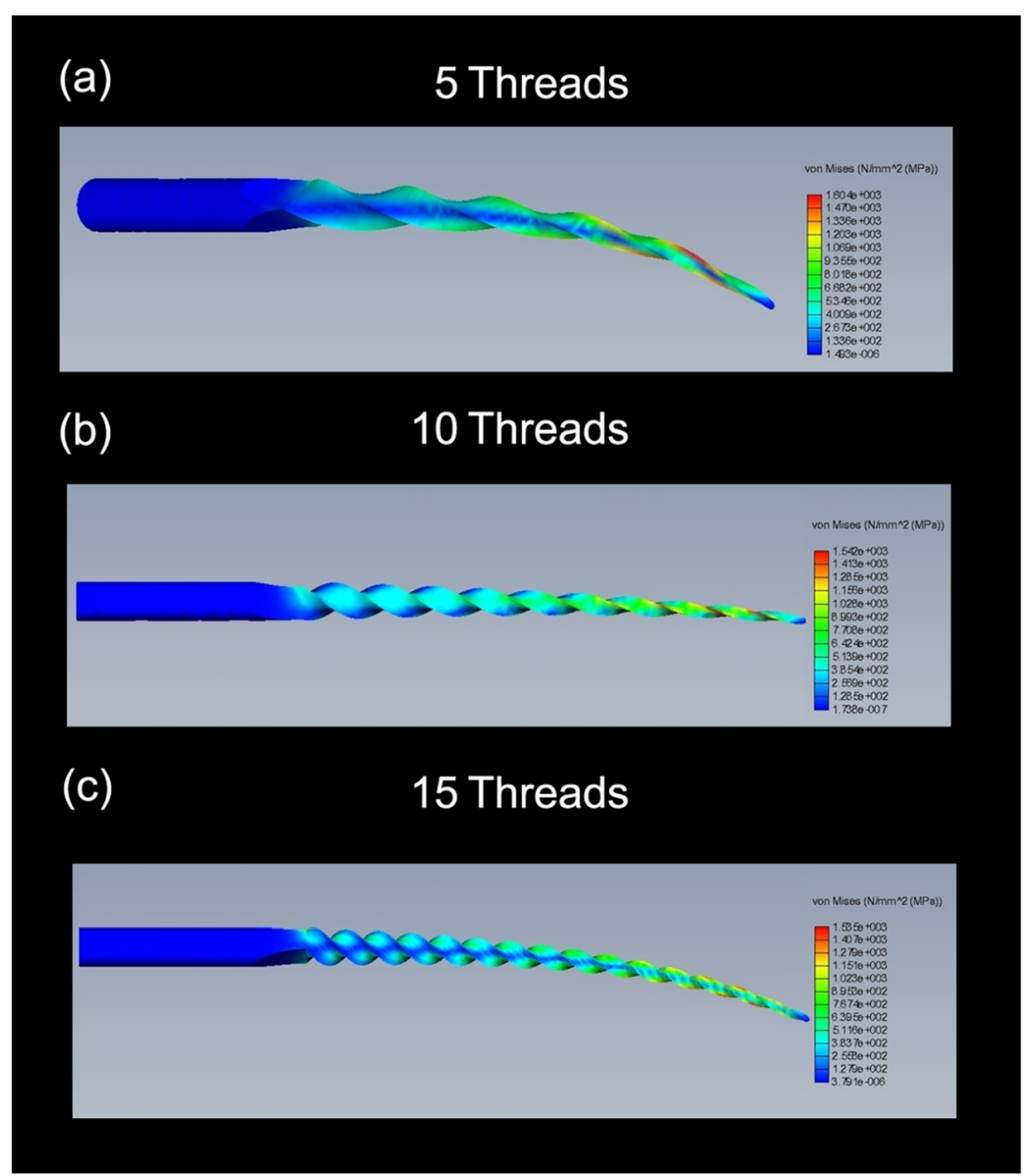

Fig. 5 Stress distribution during bending of different tested file pitch. a 5 threads. b 10 threads. c 15 threads 
surface area (Fig. 2). The four FE models were mathematically analyzed under bending and torsional conditions.

Pitch Three different models were created with the same cross section design (triangular) and same taper 0.06, but with different pitch $(5,10,15$ threads). Mathematical analysis was performed during bending and torsion.

Taper Two models were created with same crosssection design (triangular) and same pitch (10 threads), but with two different tapers: 0.04 and 0.06 . Mathematical analysis was performed during bending and torsion conditions.

\section{Centric and eccentric cross section:}

Two models were created with the same cross-section design (rectangular), same taper 0.06, and same pitch
(10 threads) but with different centricity of the cross section. Mathematical simulation was performed under bending and torsional conditions.

\section{Results}

\section{Cross-sections configuration}

The maximum von Mises stress upon bending test was observed on convex triangle cs (1962 MPa), followed by triangle cs (1535 MPa), then parallelogram cs (870 $\mathrm{MPa}$ ), while the least amount of stress was related to rectangular cs (814 MPa) (Fig. 3).

When a torsional test was performed, the maximum von Mises stresses were related to convex triangular cross section $(4321 \mathrm{MPa})$, followed by triangular cross section (4285 $\mathrm{MPa})$, rectangular cross section (2659 $\mathrm{MPa}$ ), and parallelogram (2307 MPa) (Fig. 4).

Stress distribution during bending was similar in the four models: the maximum areas of stress concentration
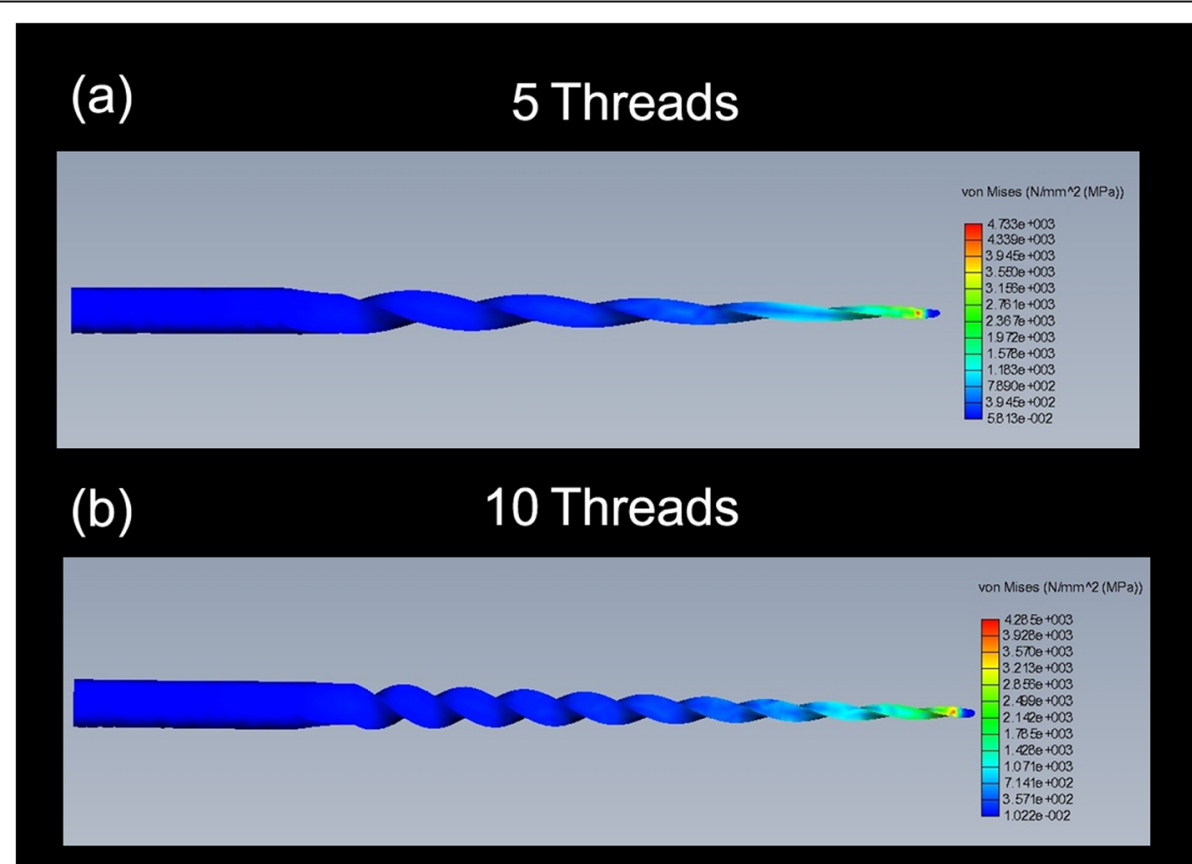

(c)

15 Threads

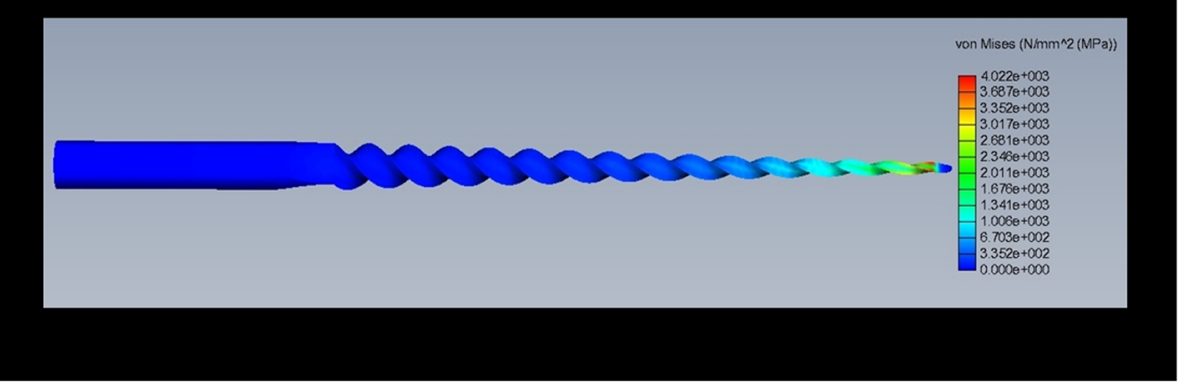

Fig. 6 Stress distribution during torsion of different tested file pitch. a 5 threads. b 10 threads. c 15 threads 
were detected in the cutting edges of the four models; however, the rectangular cs design showed areas with more stress concentration which will subject this point to failure. Stress distribution upon torsional testing was similarly related to the base of the flutes in the four models; however, it was more concentrated in the base of the flutes in the first $2 \mathrm{~mm}$ of the triangular cs design.

\section{Pitch}

During bending testing, the maximum stress was related to the 5 threads model $(1604 \mathrm{MPa})$ followed by 10 threads (1542 MPa) then 15 threads (1535 MPa). Under torsional conditions, the maximum stress was related to 5 threads model $(4733 \mathrm{MPa})$ followed by 10 threads $(4285 \mathrm{MPa})$ then 15 threads $(4022 \mathrm{MPa})$. Bending test results showed that increasing the number of threads resulted in decreasing the stress accumulation in the file models (Fig. 5). Stress distribution showed that maximum stress was related to the cutting edges, and it was more concentrated with decreasing the number of the threads.

The same results have been obtained during torsional testing as the results revealed that the increase in the number of the threads cause a decrease in the von Mises stress created in the file model both under bending and torsional conditions (Fig. 6). Stress distribution was similar in the three models, and it was related to the base of the flutes.

\section{Taper}

During bending, the maximum stress was related to the 0.06 taper model $(2443 \mathrm{MPa})$ while the 0.04 taper model $(1535 \mathrm{MPa})$ showed less stress accumulation. Under torsion, the maximum stress was related to the 0.04 taper model $(4652 \mathrm{MPa})$ and not to the 0.06 taper model (4285 MPa). Bending test results demonstrated that as the taper of the file increases, the amount of von Mises stresses increases (Fig. 7).

During the torsional testing, increasing of the taper resulted in decreasing of the amount of von Mises stress created (Fig. 8).

\section{Centricity of the cross section}

During bending, the eccentric cross-section model showed the maximum stress $(841 \mathrm{MPa})$ while centric cross-section model showed $814 \mathrm{MPa}$. During torsion

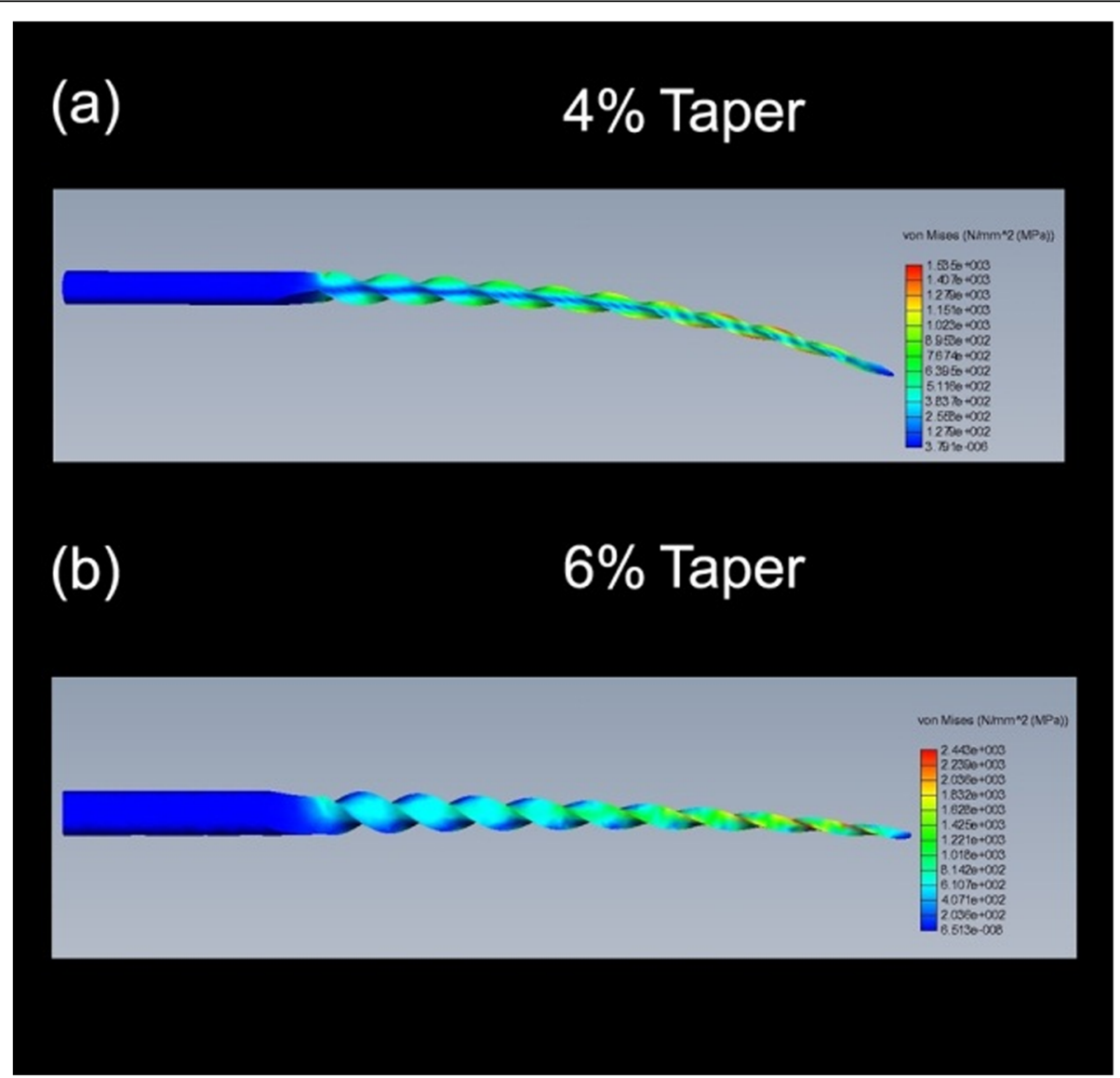

Fig. 7 Stress distribution during bending of different tested file taper. a $4 \%$ taper. b 6\% taper 


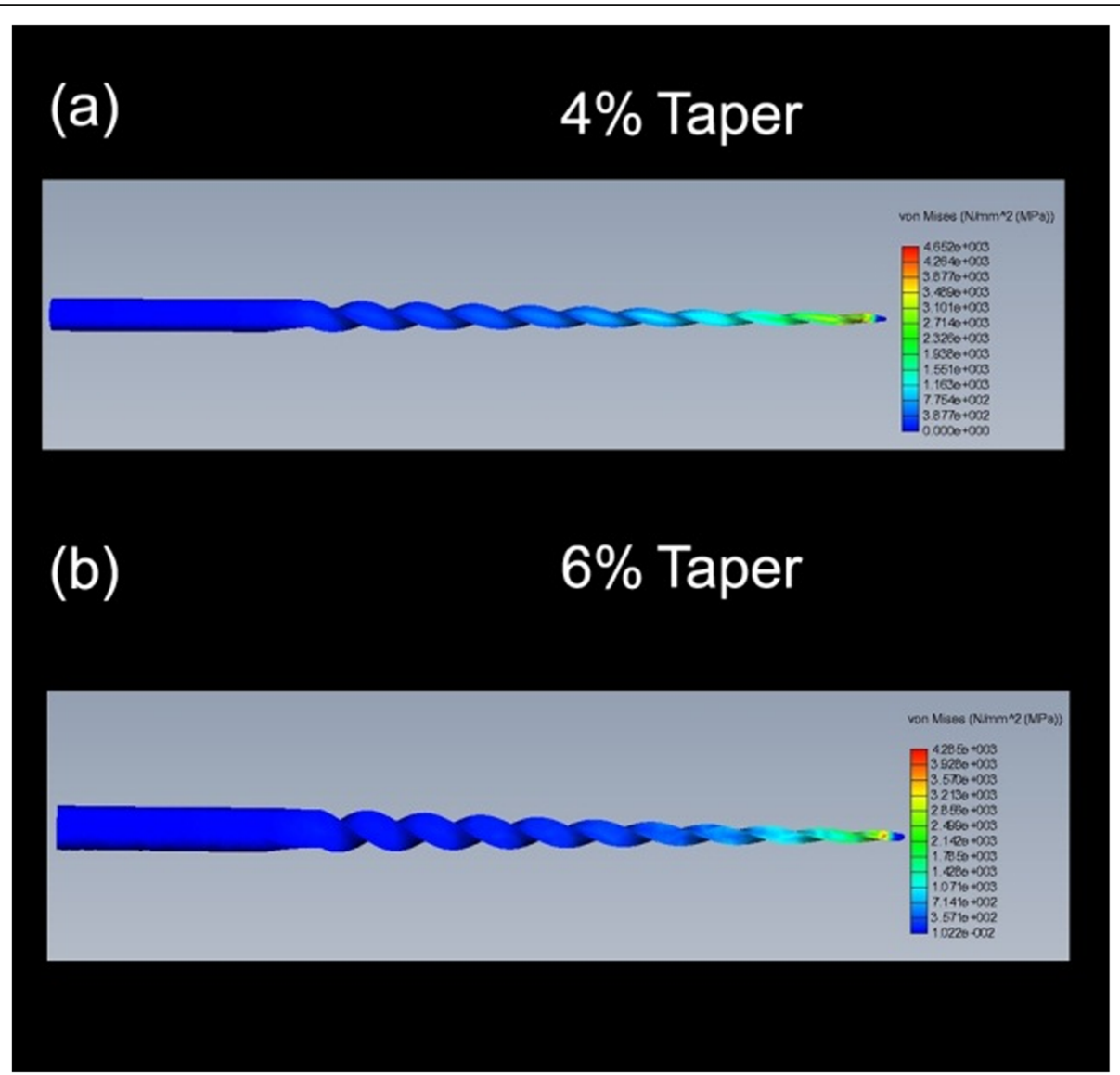

Fig. 8 Stress distribution during torsion of different tested file taper. a 4\% taper. b 6\% taper

testing, reduction in stress values have been reported in the off-centered file (eccentric) (2299 MPa) compared with centered (centric) cross-sectional file design (2659) (Figs. 9 and 10).

\section{Discussion}

FEA is a convenient tool to investigate complex endodontic stress distribution analyses (Jiang et al. 2018). Moreover, they offer the benefit to investigate each feature independently under controlled circumstances. It allows evaluation of different variables in a way that cannot be done experimentally (Versluis et al. 2012).

Improvement of NiTi rotary metallurgy and thermomechanical treatment enhance their mechanical behavior (Galal 2019; Galal et al. 2019). However, the geometrical design plays a crucial role on the mechanical behavior of NiTi rotary instruments (Kim et al. 2009b; Zhang et al. 2011; Ha et al. 2017). Geometry of NiTi rotary instrument decides their rigidity (Hamdy et al. 2019). Hence, clinical efficiency and cutting performance, as well as fracture incidence that may arise from bending or torsion stresses generation in an instrument (Montalvão et al. 2014; Omar et al. 2019).
The von Mises stress distribution along the NiTi rotary file instruments contribute to instrument fracture. The evaluation of stress distributions in the present study was done under application of simulated loading to the clinical situations. Where cantilever bending stresses simulate the file movement into curved root canals, shear moment (torsional) stresses simulate that arises inside a narrow canals when the tip of the file bind in the root canal during the rotation of shank (Necchi et al. 2010).

Kim el al. investigated the effect of the cross-sectional area on bending and torsion conditions. They showed that the increase in cross-sectional area resulted in increasing the rigidity however increasing the torsional resistance (Kim et al. 2009a). Versluis et al. evaluated the effect of cross-sectional area and geometry on the mechanical behavior of NiTi rotary instruments; they found that increasing in cross-sectional area decreased the flexibility of the NiTi rotary instruments (Versluis et al. 2012).

Increasing the cross-sectional area increased the stress accumulation during bending compared with smaller cross-sectional area. In this study, the convex triangular 


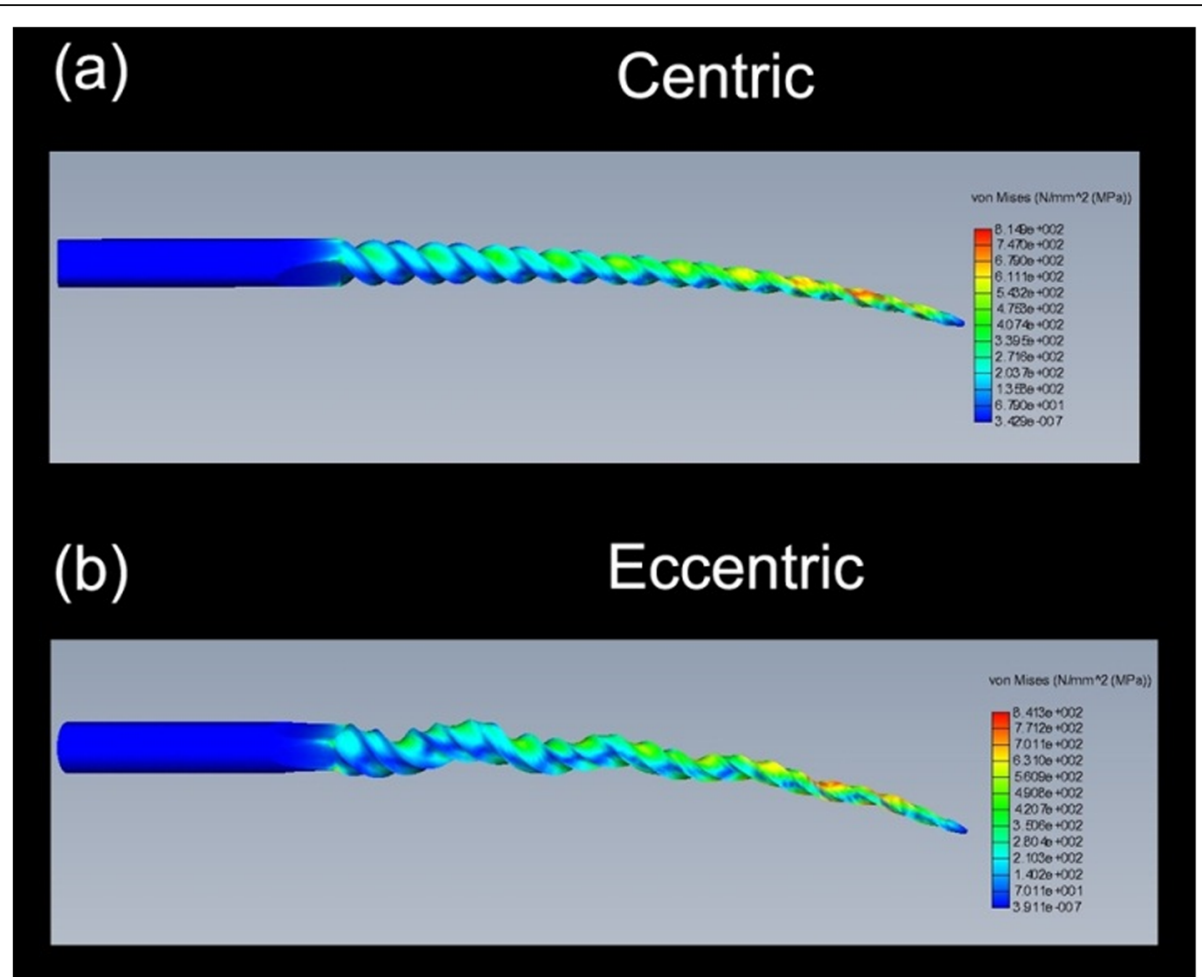

Fig. 9 Stress distribution during bending of different tested file centricity of the cross section. a Centric cs. b Eccentric cs

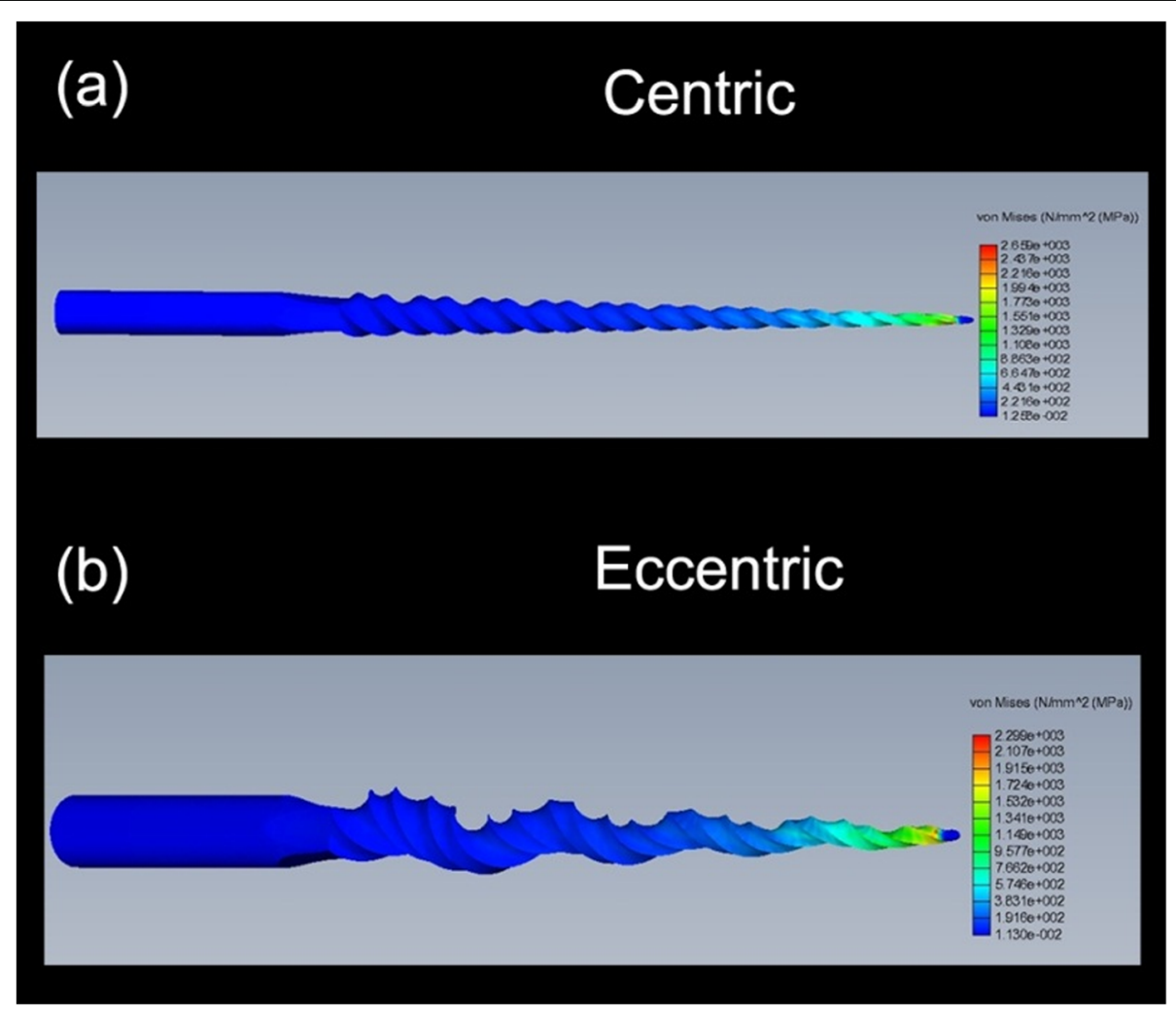

Fig. 10 Stress distribution during torsion of different tested file centricity of the cross-section. a Centric cs. b Eccentric cs 
cs design showed the maximum von Mises stress during bending and torsion; this is due to increasing the surface area and perimeter of this cs in addition to the threepoint contact with the canal walls that resulted in increased torsional fatigue while decreasing the crosssectional area may be attributed to more flexibility of the file (Kim et al. 2009a). The file model with parallelogram cross-section design showed less stress concentration during torsional testing which indicates more resistance to torsional failure; this may be due to the innovative cross-sectional design that resulted in only two-point contacts with the canal walls also decreasing its crosssectional area resulted in increasing its flexibility (Kim et al. 2009a).

Under both bending and torsional conditions, the maximum stress was related to the five threads model followed by 10 threads and then 15 threads. This may be due to the finding reported by Baek et al. that decreasing the pitch of the file (increase number of threads) increases its flexibility and thus decreases the stresses generation in both bending and torsional situations (Baek et al. 2011).

It was noticed that increasing the taper of the file results in generation of more stresses. This finding was in agreement with the results of Arbab-Chirani et al. which may be attributed to the fact that during bending test, increasing the taper of the file results in building-up of larger magnitudes of internal stresses, and also it reduces the flexibility of the file. While during torsional testing, increasing the taper resulted in reduction in the torsional fatigue (Arbab-Chirani et al. 2011).

The results showed that eccentric cross-section resulted in more stress than centric cross section during bending stress. This finding is congruent with $\mathrm{Ha}$ et al., which conclude that the flexibility of the files was reduced as the feature of off-center distance being was increased (Ha et al. 2017), while the torsional resistance increased in the eccentric cs than in the centered models. This may be due to the presence of two points of contacts with the canal wall which decreases the chance of locking the file inside the canal during root canal preparation (Ghobashy et al. 2016).

Although finite element analysis has the considerable benefit of being an accurately controlled study as mentioned previously, the results of this theoretical study might have some variations from a clinical study that derived from actual files mainly due to manufacturing process and surface irregularities (Kim et al. 2010).

\section{Conclusions}

The current study used finite element study analysis to evaluate the effects of cross-sectional shape, pitch, taper, and centricity of the cs on stress distribution upon bending and torsion on rotary NiTi instruments. Within the limitation of this in vitro study, the effects the stresses and thus the potential fracture under the applied testing conditions could not be reduced by single NiTi instrument design. Minimizing the stress accumulation under bending conditions of rotary files during preparation of curved root canals could be achieved by designed rotary NiTi instruments with rectangle cross-section configuration, low pitch, reduced taper, and with centered cross section. This design improved the flexibility of rotary $\mathrm{NiTi}$ instruments. However, to optimize the torsional resistance during root canal preparation of narrow canals, the file should be designed with parallelogram crosssectional configuration, low pitch, increased taper, and eccentric cross-section design.

\section{Abbreviations}

NiTi: Nickel-titanium; FEA: Finite element analysis; FE: Finite element; cs: Cross section

\section{Acknowledgements}

Sincere thanks to Dr. Roger Watson, Professor of Nursing, Faculty of Health Sciences, University of Hull, United Kingdom, for extending his support and help through English editing.

\section{Authors' contributions}

All authors contributed to the conception and design of the study, experimental work, interpretation of the analyzed data, and writing of the manuscript; revised and reviewed the draft manuscript. All authors read and approved the final manuscript.

\section{Funding}

The work was self-funded by the authors.

\section{Availability of data and materials}

All data generated or analyzed during this study are included in this published article.

Ethics approval and consent to participate

Not applicable.

\section{Consent for publication}

Not applicable.

\section{Competing interests}

The authors declare that they have no competing interests.

Received: 21 February 2020 Accepted: 7 July 2020

Published online: 22 July 2020

\section{References}

Arbab-Chirani R, Chevalier V, Arbab-Chirani S, Calloch S (2011) Comparative analysis of torsional and bending behavior through finite-element models of $5 \mathrm{Ni}$-Ti endodontic instruments. Oral Surgery Oral Med Oral Pathol Oral Radiol Endodontology. 111(1):115-121

Baek SH, Lee CJ, Versluis A, Kim BM, Lee W, Kim HC (2011) Comparison of torsional stiffness of nickel-titanium rotary files with different geometric characteristics. J Endod. 37(9):1283-1286

Basheer Ahamed SB, Vanajassun PP, Rajkumar K, Mahalaxmi S (2018) Comparative. J Endod. 44(4):654-658

Cheung GSP, Zhang EW, Zheng YF (2011) A numerical method for predicting the bending fatigue life of NiTi and stainless steel root canal instruments. Int Endod J. 44(4):357-361

Galal M (2019) Metallurgical effect on the mechanical behavior of rotary endodontic files using finite element analysis. Bull Natl Res Cent. 43(1):215761.

Galal M, Ismail AG, Omar N, Zaazou M, Nassar MA (2019) Influence of thermomechanical treatment on the mechanical behavior of protaper gold 
versus protaper universal (A Finite Element Study). Open Access Maced J Med Sci. 7

M. Galal, T. Nassef, S. Saber, M. Zaazou SE-A (2015) Stress distribution of three NiTi rotary files under bending and torsional conditions using a Finite Element Analysis. Ain Shams Med J. 7(1-8):1-8.

Gavini G, dos Santos M, Caldeira CL, Machado ME de L, Freire LG, Iglecias EF, et al. (2018) Nickel-titanium instruments in endodontics: a concise review of the state of the art. Brazilian Oral Research. 13:68-72.

Ghobashy A, Nagy M, Obeid M (2016) Shaping ability of single versus multi file rotary Ni-Ti systems in curved root canals. Tanta Dent J. 13(2):68

Ha J-H, Kwak SW, Kim S-K, Kim H-C (2016) Screw-in forces during instrumentation by various file systems. Restor Dent Endod. 41:304-07.

Ha JH, Kwak SW, Versluis A, Lee CJ, Park SH, Kim HC (2017) The geometric effect of an off-centered cross-section on nickel-titanium rotary instruments: A finite element analysis study. J Dent Sci. 12(2):173-178

Hamdy TM, Galal M, Ismail AG, Abdelraouf RM (2019) Evaluation of flexibility, microstructure and elemental analysis of some contemporary nickel-titanium rotary instruments. Open Access Maced J Med Sci. 7(21):3647-54.

Jiang Q, Huang Y, Tu XR, Li Z, He Y, Yang X (2018) Biomechanical Properties of First Maxillary Molars with Different Endodontic Cavities: A Finite Element Analysis. J Endod. 44(8):1283-1288

Kim HC, Kim HJ, Lee CJ, Kim BM, Park JK, Versluis A (2009a) Mechanical response of nickel-titanium instruments with different cross-sectional designs during shaping of simulated curved canals. Int Endod J. 42(7):593-602

Kim HC, Kwak SW, Cheung GSP, Ko DH, Chung SM, Lee W (2012) Cyclic fatigue and torsional resistance of two new nickel-titanium instruments used in reciprocation motion: Reciproc Versus WaveOne. J Endod. 38(4):541-544

Kim HC, Yum J, Hur B, Cheung GSP (2010) Cyclic fatigue and fracture characteristics of ground and twisted nickel-titanium rotary files. J Endod. 36(1):147-152

Kim TO, Cheung GSP, Lee JM, Kim BM, Hur B, Kim HC (2009b) Stress distribution of three NiTi rotary files under bending and torsional conditions using a mathematic analysis. Int Endod J. 42(1):14-21

Kwak SW, Lee CJ, Kim SK, Kim HC, Ha JH. Comparison of screw-in forces during movement of endodontic files with different geometries, alloys, and kinetics. Materials (Basel). 2019;12(9):1-7.

McGuigan MB, Louca C, Duncan HF (2013) Endodontic instrument fracture: causes and prevention. Br Dent J. 214(7):341-348

Medha A, Patil S, Hoshing U, Bandekar S (2014) Evaluation of forces generated on three different rotary file systems in apical third of root canal using finite element analysis. J Clin Diagnostic Res. 8(1):243-246

Montalvão D, Alçada FS, Braz Fernandes FM, De Vilaverde-Correia S (2014) Structural characterisation and mechanical fe analysis of conventional and m-wire Ni-Ti alloys used in endodontic rotary instruments. Sci World J. 2014

Necchi S, Petrini L, Taschieri S, Migliavacca F (2010) A comparative computational analysis of the mechanical behavior of two nickel-titanium rotary Endodontic instruments. J Endod. 36(8):1380-1384

Omar N, Ismail AG, Galal M, Zaazou MH, Mohamed MA (2019 Dec) A comparative finite analysis of the mechanical behavior of ProTaper NEXT and WaveOne rotary files. Bull Natl Res Cent. 43(1):148

Pasqualini D, Alovisi M, Cemenasco A, Mancini L, Paolino DS, Bianchi CC et al (2015) Micro-computed tomography evaluation of ProTaper next and BioRace shaping outcomes in maxillary first molar curved canals. J Endod. 41(10):1706-1710

Ruddle CJ, Machtou P, West JD. The shaping movement: Fifth-generation technology. Dent Today. 2013;32(4):94-99.

Rzhanov EA, Belyaeva TS (2012) Design features of rotary root canal instruments Introduction. 29 ENDO (I Engl) 6(1):29-39

Shen SM, Deng M, Wang PP, Chen XM, Zheng LW, Li HL (2016) Deformation and fracture of K3 rotary nickel-titanium endodontic instruments after clinical use. Int Endod J. 49(11):1088-1094

Tsao CC, Liou JU, Wen PH, Peng CC, Liu TS (2013) Study on bending behaviour of nickel-titanium rotary endodontic instruments by analytical and numerical analyses. Int Endod J. 46(4):379-388

Versluis A, Kim HC, Lee W, Kim BM, Lee CJ (2012) Flexural stiffness and stresses in nickel-titanium rotary files for various pitch and cross-sectional geometries. J Endod. 38(10):1399-1403

Zhang EW, Cheung GSP, Zheng YF (2011) A mathematical model for describing the mechanical behaviour of root canal instruments. Int Endod J. 44(1):72-76

\section{Publisher's Note}

Springer Nature remains neutral with regard to jurisdictional claims in published maps and institutional affiliations.

\section{Submit your manuscript to a SpringerOpen ${ }^{\circ}$ journal and benefit from:}

- Convenient online submission

- Rigorous peer review

- Open access: articles freely available online

- High visibility within the field

- Retaining the copyright to your article

Submit your next manuscript at $\boldsymbol{\nabla}$ springeropen.com 